\title{
Maimon M. Cohen, PhD
}

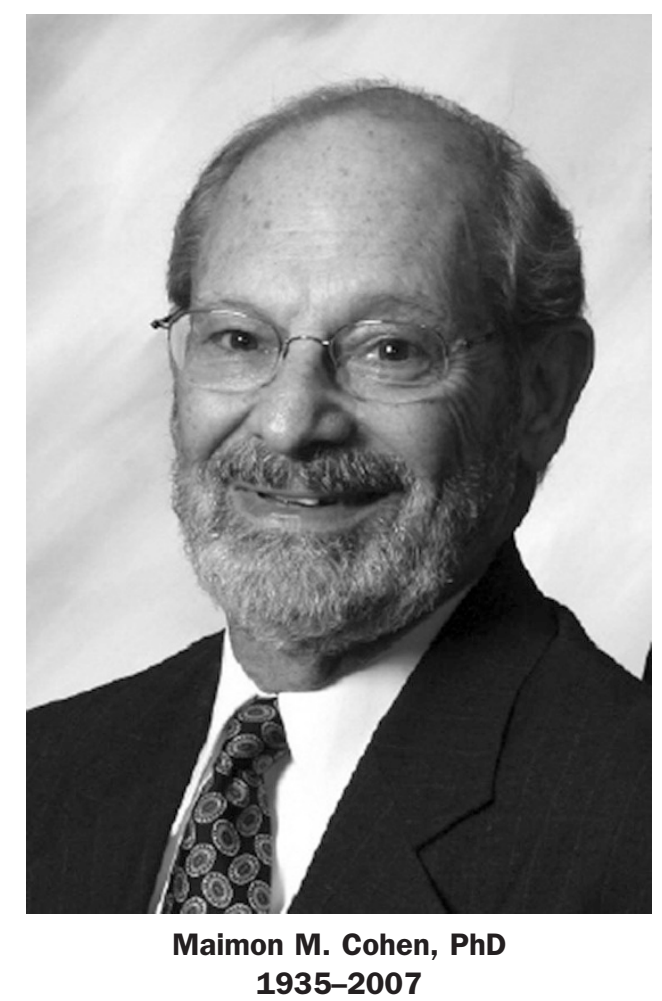

The human genetics community has lost one of its giants. Maimon Cohen was an early leader in the field of human genetics and played a pivotal role in its growth and development. His national and international impact was extraordinary, both in science and in education.

He grew up in Baltimore, Maryland, where he earned his bachelor's degree in Semitic languages from Johns Hopkins University in 1955. Dr. Cohen planned to be an agronomist and earned a master's degree in 1959 and a doctorate in crop genetics from the University of Maryland in 1962 . He planned to move to Israel to practice crop genetics, but during a postdoctoral fellowship at the University of Michigan, he became interested in human genetics. There, under the tutelage of Margery Shaw, he became an accomplished cytogeneticist.

In 1965, he moved to the Department of Pediatrics at the State University of New York at Buffalo as the Director of Cytogenetics in the Division of Human Genetics and quickly rose to the rank of Associate Professor of Pediatrics and Microbiology in 1968. In addition to a number of fundamental discoveries in human cytogenetics in Buffalo, he also wrote a fascinating article on the chromosomes of five crocodilian species. He showed a broad interest in other aspects of biology, includ- ing a series of experiments in mice published by him and Anil Mukherjee in Nature in 1970 that was perhaps the first demonstration that in vitro fertilization does not have deleterious effects on the embryo.

In 1972, Dr. Cohen was appointed Professor and Chairman of the Department of Human Genetics at Hadassah Hebrew University Medical School in Jerusalem, where he developed a vibrant department and where his legacy remains evident to this day. In that year, he was also the lead author in the publication of the first of the vital books on standardization of human cytogenetics. In Israel, he continued to be a leader in the study of chromosomes and somatic cell genetics and became involved in the clinical and biochemical descriptions of a number of genetic disorders. A major article written with his successor in the chair, Gideon Bach, demonstrated the basic biochemical defect in mucolipidosis IV.

In 1979, he returned to the United States as Associate Head of the Division of Genetics for the Children's Memorial Hospital in Chicago and was appointed Professor of Pediatrics at Northwestern University Medical School. While continuing collaboration and publishing articles with his Israeli colleagues, Dr. Cohen began a series of experiments with his Chicago associates on chemical and radiation sensitivity in cells 
from patients with ataxia telangiectasia and other chromosomal breakage syndromes.

In 1982, Dr. Cohen became the Chief of the Division of Human Genetics at the University of Maryland School of Medicine and Professor of Obstetrics and Gynecology, and Pediatrics. Other positions during his stay at the University of Maryland were a professorship in the Medical Biotechnology Center, Vice Chair of Obstetrics and Gynecology, and Professor of Pathology. While at Maryland, he trained and collaborated with a number of cytogeneticists and human geneticists including such leaders in the field as Stuart Schwartz, Joel Charrow, Susan Panny, Miriam Blitzer, and the present Executive Vice President of the American Society for Human Genetics, Joann Boughman. During this period, Dr. Cohen continued his important work in human and animal cytogenetics and furthered our understanding of chromosome damage caused by a variety of environmental factors.

In 1998, he became the first director of the Harvey Institute for Human Genetics at the Greater Baltimore Medical Center, where he developed a busy and highly respected cytogenetic service laboratory and continued to publish original articles in human cytogenetics.

Dr. Cohen made enormous contributions to the evolution of genetics into a full medical and scientific specialty. He was elected to a number of important officerships, including Director, Treasurer, and President of the American Society of Human Genetics, the latter in 1994. He was one of the orga- nizers of the American College of Medical Genetics and was one of its Directors for 7 years, during which time he was the Vice President for Laboratory Genetics. Dr. Cohen had a major interest in governmental affairs. In 1995, he spent a year as a Legislative Assistant, Health Affairs, to U.S. Senator Paul D. Wellstone, as an American Association for the Advancement of Science and Engineering Congressional Fellow, sponsored by the American Society of Human Genetics. He held numerous grants in both the United States and Israel and published 221 peer-reviewed articles in the most prestigious journals in our field.

Maimon Cohen was one of the great leaders in the field of human genetics and most particularly in human cytogenetics. A man of indomitable spirit, Dr. Cohen is remembered by his colleagues and friends for his enormous energy, his inspirational leadership, and his compassionate mentoring skills. He is survived by Barbara, his wife of 51 years; their three sons, Neri, Akiva, and Noam; and their families. Each of their sons is continuing Maimon's commitment to science. His legacy is permanent. We will all miss him and his intelligence and humor.

Kurt Hirschhorn MD, ${ }^{1}$ Michael Kaback MD, ${ }^{2}$ and David Rimoin MD, $\mathrm{PhD}^{3}$

${ }^{1}$ Mt. Sinai School of Medicine, New York, New York;

${ }^{2}$ University of California, San Diego School of Medicine, San Diego, California; ${ }^{3}$ Cedars-Sinai Medical Center, Los Angeles, California 